\title{
The ENT case report in the era of evidence-based medicine: a defence and a guide
}

Is there any continuing value in case reports? There is certainly a trend in the medical publishing world away from such articles and in favour of papers and studies that present higher level evidence. The Journal of Laryngology \& Otology continues to publish case reports in the belief that there is still a place for the presentation of a clinically important and unique experience, especially if the report carries a clearly defined message to the reader. However, the criteria for successful submission need to be refined, as the need for novelty and rarity must be balanced against the paper's relevance to common practice.

The problem is that the humble case report is often derided as being unscientific and of little value either to the reader or, indeed, to the author's reputation. However, rumours of its demise may be somewhat premature. Indeed, there is a long and honourable tradition of presenting case examples in medical teaching and of deriving general lessons from a particular and individual experience. Just as the legal system seeks precedents, a good case report may be a useful starting point in the hierarchy of evidence, and the current emphasis on higher level research may lead us to forget that clinical practice may sometimes be influenced by a single patient or index case in the community.

Case reports have been categorised into four types. $^{2}$

The first type is the momentous and historic paper. Such articles include Jenner's description of vaccination, Billroth's pioneering gastrectomy and Lister's account of antisepsis. Case reports of this kind are rare.

The second type is the educational paper, which includes potential mishaps, risk management and the 'lesson of the week' format.

The third type is the bizarre case, which is published for entertainment value. It would be a sad journal that could not occasionally find some space for an article entitled 'Temporal bone fracture following blunt trauma caused by a flying fish' - as in The Journal of Laryngology \& Otology in $1998 .^{3}$

The fourth type of case report, comprising the majority, communicates a single rare event or association presented in isolation rather than incorporated into a pattern of disease. Such case reports lack an analytic approach. Even if they do describe a unique phenomenon which has never before been encountered or reported in a century of medical literature, they may have little relevance, as there is small likelihood of the same sort of case being encountered in the reader's practice.

\section{The Editor's view}

The JLO currently accepts one-third of all articles submitted, but there is an acknowledged preference for publishing more main articles and fewer case reports, with the latter increasingly appearing as 'online only'. ${ }^{4}$ In 2007, this journal published 174 Main Articles and 84 Clinical Records, compared with 144 and 110, respectively, in 2006, and this downward trend continues.

Case reports have a limited appeal to journal editors. ${ }^{5}$ It is true that they provide good 'fillers', need little editing and can be inserted as the need arises, as they are not at risk of becoming outdated. There is an entertainment and 'easy reading' factor associated with the majority of them, especially if they are well illustrated, and this may make a case report more likely to be read - even if it is never cited thereafter - than the best researched meta-analysis. Thus, of the 50 most popular JLO articles viewed online as abstracts or full text in 2007, 10 were case reports.

The worldwide trend in medical publishing away from case reports may be due to the influence of the impact factor. This, the concept of Eugene Garfield in 1955, is updated annually by the Institute for Scientific Information in Philadelphia. The impact factor is derived from two elements. The numerator is the number of citations in the world literature during that current year to any items published in the journal in the previous two years. ${ }^{6}$ The denominator is the number of substantive articles which the journal published in those same two years. The ratio derived therefore attempts to predict the number of times any article will be cited in the next two years. For the 30 cited ENT journals, the 2006 impact factor varied from 0.368 for the Journal of Otolaryngology, to 0.561 for The Journal of Laryngology \& Otology, to the highest, 1.736 for Laryngoscope. The impact factor has its critics and, indeed, it can be inflated by favouring longer articles and reviews, which are more often cited than are case reports. A short lag to publication helps, and journals in the United States benefit from a well documented parochial approach to citations amongst US authors. Self-citation is not corrected, so a policy of publishing editorials, which cite previous articles or even other

First published online 11 August 2008. 
editorials from the same journal, is an advantage to a cynical editor! ${ }^{7}$ Indeed, the Institute for Scientific Information has calculated that 80 per cent of all articles published in scientific journals are cited once or less, and that between 5 and 20 per cent of these are self-citations. ${ }^{8}$

Comparison of the four highest impact ENT journals (all from the US) with publications from other specialties shows no greater trend towards case reports. Indeed, there is a move towards more basic scientific research and prospective studies, even if ENT studies use much smaller sample sizes. ${ }^{9}$

There is thus a developing bias against accepting case reports, and this has been mirrored in a decline in case report submissions to this journal over the last three decades. An interesting study comparing three cohorts of US otolaryngologists, who completed training in the 1970s, 1980s and 1990s, assessed their literary output in their first five years of practice; it showed a statistically significant decline in the number of published case reports, from 1.7 to 0.9 per author. ${ }^{10}$

A review of UK publishing trends showed that, in a three year period (1997-1999), British authors published 248 case reports (compared with a total of 687 articles) in the eight ENT journals with the highest impact factors. No fewer than 230 of these case reports appeared in the JLO. ${ }^{11}$ 'Online only' publication, increasingly the JLO policy for case reports, will still ensure rapid publication and allow sharing of experience, without diluting the content of the printed journal.

The case report appears in many guises, whether 'lesson of the week', 'radiology in focus' or 'imaging case of the month'. An old gag describes one case as 'in my experience', two as 'in my series' and three as 'time after time after time'. Indeed, scrutiny of the most prestigious journals shows that they are not above publishing accounts of some very small 'series', together with a review of the literature, as scientific articles (but certainly not as case reports).

\section{The author's view}

Submissions for publication as JLO Clinical Records must, therefore, withstand an increasingly rigorous peer review process. The presentation must be of a high standard if a great deal of effort is not to be met with disappointment. While the case report has long been seen as an opportunity for novice academics to 'wet their feet' in medical writing ${ }^{12}$ - even if only to provide padding for their curriculum vitae care in adhering to the correct format, as outlined in the 'Instructions to Authors', is more likely to result in success and acceptance. Unfortunately, submission is usually a retrospective exercise that is delegated to the most junior trainee, with the inherent problem that much of the required data are either missing or were never documented initially. There is an art to spotting the potentially unusual at an early stage and thereafter ensuring adequate investigation, with documentation of the outcome and follow up.

The successful case report author will decide, well before putting pen to paper, what new message for clinical management their report will convey ${ }^{13}$ and what aspects of the account will influence practice and inform others. If such elements are clearly stated, as a single sentence in the abstract, the editor's interest may then be stimulated.

\section{The peer reviewer's view}

In these reviewers' experience, the commonest failings of case reports include the following.

\section{Lack of proofreading}

Many journals will undertake this to a limited degree, especially for non-English speaking authors. However, Bill Gates has done much to help the writer, and if the Microsoft Word Processor underlines most of the text with green and red lines, some attention as to why this should be so might be wise prior to submission. If the text is incomprehensible, especially if this suggests that it has not been read even by all the stated authors, the case report will not succeed. Commercial copy-editors can salvage a paper by providing language correction and enhancing the grammar, spelling and readability. Alpha Science Editors have been appointed the recommended copy editors to The Journal of Laryngology \& Otology and are flagged as such on our home page (http://www.jlo.co.uk).

\section{Poor quality illustrations}

Illustrations and scans need to be professionally reproduced, and the pictures should complement the text. They add interest, but their role in getting the message across must be readily apparent.

\section{Failure to establish novelty}

Experience warns both against claiming a 'first' and also against proposing inappropriate recommendations for management based on a single case, possibly from an inexperienced or trainee author or authors. ${ }^{14}$ Certainly, any claim to a unique case, using the all too common phrase 'to our knowledge this is the first report of...', should be justified by a description of the search strategy employed, lest outraged correspondents later quote precedence. Equally, the first ever description of a laryngeal lesion does not realistically justify the statement that 'this must now be considered in the differential diagnosis of...'.

\section{Too many cooks}

The listing of an increasing number of authors for even the simplest clinical record is to be discouraged. Each author's contribution to the work should be documented and published. An author should satisfy all of the following criteria: (1) contribution to the concept and design of the project, or analysis and interpretation of the data; (2) contribution to the drafting or critical revision of the manuscript content; and (3) participation in final approval of the version submitted.

All other contributions (e.g. funding, supervision of the research group, or acting as departmental 
chair or chief) may merit acknowledgement - but not authorship. ${ }^{15}$

\section{Failure to adhere to 'Guidelines to Authors'}

It is surprisingly common to receive a case report that has obviously been prepared in the 'house style' of another journal, and which has clearly been subsequently touted around in desperation. Such carelessness just invites further disappointment!

\section{Breach of ethical standards}

Although fortunately less likely than in the research techniques of prospective studies, ethical problems are still encountered in the process of case report submission. Redundant or duplicate publication can generally be detected by peer reviewers in this age of online literature review. Patient confidentiality, especially regarding publication of identifiable illustrations, must be considered. Plagiarism, scientific fraud and lack of patient consent are potentially subject to sanctions from an international editorial consortium. ${ }^{16}$

Novice authors are encouraged to peruse a copy of Writing and Publishing in Medicine by E J Huth, a mine of information on paper preparation. ${ }^{17}$

\section{Conclusion}

An editorial policy that favours systematic reviews and prospective, controlled trials over case reports will surely be increasingly seen as the hallmark of excellence in scientific publishing. If it is to be accepted by the editor and then the reader, the ENT case report of the future will need to carry a novel, well argued and important clinical message, and will need to be prepared to the same standards as are expected for submission of clinical experimentation.

\section{References}

1 Jenicek M. Clinical case reports: sources of boredom or valuable pieces of evidence? National Medical Journal of India 2001;14:193-4

2 Monk B. Case reports: a section's view. J R S Med 1995; 88:278

3 Goldenberg D, Marwan K, Danino J, Flax-Goldenberg R, Joachims H. Temporal bone fracture following blunt trauma caused by a flying fish. J Laryngol Otol 1998; 112:959-61

4 Youngs R, Kenyon G. Back to the future: the JLO electronic archive. J Laryngol Otol 2008;122;1-2

5 Nahum AM. The clinical case report: "pot boiler" or scientific literature? Head Neck Surg 1979;1:291-2

6 Garfield E. The history and meaning of the Journal Impact Factor. JAMA 2006;295:90-3

7 Seglen PO. Why the impact factor of journals should not be used for evaluating research. BMJ 1997;314:498-502

8 Spector JG. Present and future considerations in otolaryngologic publishing. Laryngoscope 1994;104:651-5

9 Bhattacharyya N. Peer review: studying the major otolaryngology journals. Laryngoscope 1999;109:640-4

10 Bhattacharyya N, Shapiro NL. Academic otolaryngology in the new millennium: are we falling behind? Otolaryngol Head Neck Surg 2001;124:4-8

11 Sandhu GS, Wright A. Publishing trends in otolaryngology from January 1997 to December 1999 in the UK. Clin Otolaryngol 2001;26:249-52

12 Har-El G. Does it take a village to write a case report? Otolaryngol Head Neck Surg 1999;120:787-8

13 Kenyon G. How I select a paper for publication. ENT News 2005;13:70-1

14 Treasure T. What is the place of the clinical case report in medical publishing? J R Soc Med 1995;88:279

15 Bailey BJ. What is an author? Otolaryngol Head Neck Surg 2001;124:2-3

16 Youngs R, Kenyon G. Maintaining ethical standards in medical publishing. J Laryngol Otol 2006;120:1-2

17 Huth EJ. The case report and case series analysis. In: Huth EJ. Writing and Publishing in Medicine, 3rd edn. Baltimore: Williams \& Wilkins, 1999;103-10

LIAM M FLOOD

G KENYON 